\title{
UPAYA MENINGKATKAN HASIL BELAJAR MATEMATIKA MELALUI PENDEKATAN SCIENTIFIC DENGAN PEMBELAJARAN COOPERATIVE LEARNING PADA SISWA KELAS IV SEKOLAH DASAR
}

\author{
Riduan Febriandi \\ STKIP PGRI Lubuklinggau \\ riduanfebriandi9@gmail.com
}

\begin{abstract}
ABSTRAK
Penelitian ini bertujuan untuk meningkatkan hasil belajar Matematika siswa kelas IV melalui pendekatan Saintifik dengan pembelajaran Cooperative learning di SDN 58 Lubuklinggau. Jenis penelitian ini adalah Penelitian Tindakan Kelas (PTK). Penelitian ini menggunakan pendekatan Saintifik dengan Pembelajaran Cooperative learning. Data diperoleh dari hasil penelitian, hasil observasi dalam pembelajaran menggunakan pendekatan Saintifik dengan pembelajaran kooperatif. Teknik analisis data menggunakan deskriptif kualitatif. Hasil penelitian menunjukkan bahwa hasil belajar Matematika siswa mengalami peningkatan. Ini didukung oleh penggunaan pendekatan Saintifk dengan pembelajaran kooperatif yang menekankan pada 5 aspek yaitu mengamati, bertanya, mencoba, menalar dan berkomunikasi. Peningkatan rata-rata hasil belajar siswa terlihat dari hasil refleksi awal sebesar 43,66 pada siklus pertama naik menjadi 71,43, siklus kedua naik menjadi 76,84 dan pada siklus ketiga naik menjadi 81,72. Pada refleksi awal dari persentase ketuntasan sebesar 21,43\% atau 6 dari 28 siswa, pada siklus pertama meningkat menjadi 50\% atau 14 dari 28 siswa, kemudian pada siklus kedua meningkat $60,71 \%$ atau 17 dari 28 siswa dan pada siklus ketiga meningkat $85,71 \%$. Dapat disimpulkan bahwa ada peningkatan hasil belajar Matematika melalui pendekatan Saintifik dengan pembelajaran pembelajaran kooperatif pada siswa kelas IV SD.
\end{abstract}

Kata Kunci: Pembelajaran Matematika, Pendekatan Saintifik, Pembelajaran Kooperatif

\section{ABSTRACT}

This study aims to improve mathematics learning outcomes of fourth grade students through the Scientific approach with cooperative learning in SDN 58 Lubuklinggau. This type of research is Classroom Action Research (CAR). This study uses a scientific approach to Cooperative Learning. Data obtained from the results of research, observations in learning using Scientific approaches with cooperative learning. The data analysis technique uses descriptive qualitative. The results showed that student mathematics learning outcomes have increased. This is supported by the use of the Saintifk approach with cooperative learning which emphasizes 5 aspects namely observing, asking, trying, reasoning and communicating. The increase in average student learning outcomes can be seen from the results of the initial reflection of 43.66 in the first cycle rose to 71.43, the second cycle rose to 76.84 and in the third cycle rose to 81.72. In the initial reflection of the percentage of completeness of $21.43 \%$ or 6 of 28 students, in the first cycle increased to $50 \%$ or 14 of 28 students, then in the second cycle increased by $60.71 \%$ or 17 of 28 students and in the third cycle increased by $8571 \%$. It can be concluded that there is an increase in Mathematics learning outcomes through the Scientific approach with cooperative learning in grade IV elementary school students.

Keywords: Math Learning Outcames, Scientific Approach, Cooperative learning 


\section{PENDAHULUAN}

Belajar adalah suatu proses yang dilakukan untuk mendapatkan suatu ilmu, baik ilmu yg sudah ada, ilmu yang baru maupun pengembangan suatu ilmu dalam mencapai tujuan hidup yang lebih baik. Matematika adalah cabang ilmu yang terus dipelajari dari sekolah dasar hingga perguruan tinggi agar dapat memecahkan suatu permaslahan dengan teratur dan terstruktur. Matematika merupakan salah satu bidang studi yang menduduki peranan pentingdalam pendidikan, karena Matematika dapat memberikan banyak informasi yang disampaikan dalam bentuk bahasa symbol serta dapat digunakan untuk menyajikan informasi dalam berbagai cara, bahkan Matematika merupakan cara untuk berpikir logis,sistematis, dan konsisten (Hardiyanti: 2018). Matematika merupakan suatu bahasa sismbol; ilmu yang bersifat deduktif; ilmu mengenai tentang pola keteraturan, dan struktur organisasi, mulai dari unsur yang tidak didefenisikan, ke aksioma atau postulat, dan akhirnya menjadi sebuah dalil atau konsep (Heruman, 2008).

Berdasarkan kurikulum 2013, tujuan pembelajaran berdasarkan Standar kompetensi Lulusan SD yang diharapkan tercapai meliputi: a) Domain Sikap: memiliki perilaku yang mencerminkan sikap orang beriman, berakhlak mulia, percaya diri, dan bertanggungjawab dalam berinteraksi secara efektif dengan lingkungan sosial dan alam di sekitar rumah, sekolah, dan tempat bermain. b) Domain Keterampilan: memiliki kemampuan pikir dan tindak yang efektif dan kreatif dalam ranah abstrak dan konkret sesuai dengan yang ditugaskan kepadanya. c) Domain Pengetahuan: memiliki pengetahuan faktual dan konseptual dalam ilmu pengetahuan, teknologi, seni, budaya, humaniora, dengan wawasan kebangaan, kenegaraan, dan peradaban terkait fenomena dan kejadian di lingkugan rumah, sekolah, dan tempat bermain.

Dalam beberapa kesempatan pembelajaran Matematika masih ditemukan bahwa metode kuno atau konvensional menjadi rutinitas di dalam kelas yang mengakibatkan siswa semakin jenuh dan kurangnya minat belajar, tambah lagi metode drill yang mengharuskan siswa mengerjakan soal yang banyak mengakibatkan tekanan besar pada siswa, akibatnya siswa mudah jenuh dan kurang kreatif. Sehingga di Sekolah Dasar terkesan bahwa Matematika hanya pelajaran hafalan rumus-rumus sebelum siswa ujian bukan sebaliknya bagaimana siswa memahami persoalanpersoalan yang mampu dipecahkan dengan menggunakan matematika. Hal itulah yang menyebabkan pembelajaran kurang optimal, siswa menjadi pasif karena pembelajaran begitu membosankan dan siswa merasa tertekan sehingga pemahaman konsep siswa dan kualitas proses pembelajaran Matematika siswa masih rendah dibawah angka kriteria ketuntasan minimal. Dari fenomena-fenomena tersebut seorang guru harus peka terhadap kebutuhan peserta didik. Guru yang inovatif harus mampu menyikapi agar masalah yang dialami peserta didik dapat teratasi.

Bintari dkk (2014) mengemukakan bahwa pembelajaran berpendekatan saintifik adalah pembelajaran yang dirancang secara prosedural sesuai dengan langkah-langkah umum kegiatan ilmiah. Pembelajaran menggunakan pendekatan saintifik yang diterapkan dikurikulum 2013 menyesuaikan dengan peradaban zaman, dimana dalam proses belajar membiasakan siswa untuk berperan aktif dalam mengumpulkan fenomena- fenomena atau situasi spesifik yang kemudian ditarik sebuah kesimpulan secara keseluruhan. Pendekatan saintifik juga dapat diajarkan dengan metode kooperatif untuk menarik minat siswa.

Pembelajaran cooperative learning akan membawa siswa belajar berkelompok dimana belajar Matematika itu tidak menakutkan dan sulit, justru siswa akan merasa termotivasi untuk belajar. Sesuai yang dikmukakan oleh Rusman dalam (Indrastoeti \& Mahfud 2015). Pembelajaran kooperatif (cooperative learning) merupakan bentuk pembelajaran dengan cara siswa belajar dan 
bekerja dalam kelompok-kelompok kecil secara kolaboratif yang anggotanya terdiri dari empat sampai enam orang dengan struktur kelompok yang bersifat heterogen.

Diharapkan hasil belajar siswa akan meningkat setelah mengikuti proses pembelajaran yang tak lagi membosankan. Maka saya tertarik menggunakan pembelajran cooperative learning , hal ini juga didukung oleh Khusus dalam hal ini saya tertarik ingin melakukan penelitian dengan judul upaya meningkatkan hasil belajar Matematika melalui pendekatan scientific dengan pembelajaran cooperative learning pada siswa kelas IV SDN 58 Lubuklinggau. Dengan harapan proses pembelajaran lebih efektif dan hasil belajar siswa menjadi lebih baik.

\section{METODE PENELITIAN}

Penelitian Tindakan Kelas (PTK) ini dilaksanakan di SD Negeri 58 Lubuklinggau yang beralamatkan di Jl. Yos Sudarso Kelurahan Simpang Periuk. Penelitian dilaksanakan pada semester ganjil tahun pelajaran 2017/2018. Subjek dari penelitian ini adalah siswa kelas IV.C SD Negeri 58 Lubukinggau. Teknik pengumpulan data yang digunakan dalam penelitian ini adalah observasi, wawancara, dokumentasi dan tes. Pada penelitian ini, teknik validitas data yang digunakan dalam rancangan penelitian ini adalah validitas isi. Uji validitas isi digunakan untuk menunjukkan sejauh mana siswa menguasai materi pelajaran yang disampaikan dalam pembelajaran.

Hal ini sesuai dengan yang disampaikan oleh Sugiyono (2009) mengungkapkan bahwa validitas isi dapat dilakukan dengan membandingkan antara isi instrument dengan materi pelajaran yang telah diajarkan. Penelitian ini dilaksanakan dalam tiga kali pertemuan atau tiga siklus. Setiap siklus terdiri empat tahapan sebagai berikut: 1) perencanaan (planning); 2) pelaksanaan tindakan (action); 3) observasi dan evaluasi tindakan (observation and evaluation); dan 4) refleksi tindakan (reflecting). Sejalan dengan yang dikemukakan Rahmawati Adapun tahaptahap PTK adalah perencanaan, pelaksanaa, pengamatan dan refleksi (2016).

Bahan dan alat yang digunakan saat mengajar dalam penelitian ini adalah Laptop, Infocus, aplikasi Power Point dan Wifi Mouse, serta benda-benda permainan anak-anak seperti: kelereng, stick, kartu dan karet gelang. Semua itu digunakan untuk media pembelajarn berkelompok dengan mengaitkan benda sesungguhnya yang mudah dijumpai untuk dijadikan media pembelajaran yang menyenangkan.

\section{HASIL PENELITIAN}

Berdasarkan hasil observasi atau wawancara sebelum tindakan peneliti mendapatkan keterangan bahwa guru masih menggunakan model dan metode maupun teknik pembelajaran yang konvensional sehingga nilai rata-rata siswa yang diambil saat sebelum penelitian di kelas IV.C pada umumnya masih rendah, terbukti dari hasil nilai pemahaman konsep mengenai kelipatan dan faktor, terdapat 6 dari 28 atau 21,48\% siswa yang tuntas dengan rata-rata $(43,66)$ yang mencapai nilai $\geq 70$, selain itu pembelajaran yang konvensional menyebabkan siswa kurang aktif dalam pembelajaran sehingga ini menjadi indikasi bahwa pembelajaran Matematika pada umumnya kurang berkualitas. Pembelajaran yang membuat siswa merasa bosan dan kurang tertarik juga merupakan salah satu faktor eksternal yang dialami siswa, sehingga minat belajar siswa kurang meningkat akibatnya hasil belajar siswa tidak sesuai dengan apa yang diharapkan pada indikator pembelajaran. 
Tabel 1

Frekuensi Data Nilai Awal siswa Kelas IV.C SDN 58 Lubuklinggau

\begin{tabular}{cccc}
\hline No & Interval & Frekuensi & $\begin{array}{c}\text { Persentase } \\
(\%)\end{array}$ \\
\hline 1 & $4-16$ & 6 & 21,4 \\
\hline 2 & $17-29$ & 7 & 25,8 \\
\hline 3 & $30-42$ & 5 & 17,9 \\
\hline 4 & $43-55$ & 3 & 10,7 \\
\hline 5 & $56-68$ & 1 & 2,8 \\
\hline 6 & $69-81$ & 6 & 21,4 \\
\hline & Jumlah & 28 & 100 \\
\hline
\end{tabular}

Berdasarkan tabel diatas dapat diketahui bahwa sebelum dilaksanakan tindakan pembelajaran Matematika melalui pendekatan scientific dengan pembelajaran cooperative learning hasil belajar siswa masih tergolong rendah dimana hanya terdapat 6 siswa yang tuntas nilainya diatas 70 yang merupakan KKM dari pelajaran matematika. Artinya terdapat $21,4 \%$ yang sudah memperoleh nilai $\geq 70$, dengan demikian terdapat $78,6 \%$ siswa masih dibawah nilai $\mathrm{KKM}$ atau $<$ 70.

Analisis dari data nilai Matematika yang diambil sebelum dilakukan tindakan pembelajaran Matematika melalui pendekatan scientific dengan pembelajaran cooperative learning terdapat 22 siswa yang dikategorikan belum tuntas. Hal itu menunjukkan bahwa pemahan siswa terhadap konsep Matematika masih rendah kerena aktivitas belajar yang kurang inovatif sehingga hasil belajar siswa belum mencapai klasikal ketuntasan yang diharapkan.

Tabel 2

Frekuensi data nilai siswa kelas IV.C SDN 58 Lubuklinggau pada siklus I

\begin{tabular}{cccc}
\hline No & Interval & Frekuensi & $\begin{array}{c}\text { Persentase } \\
(\%)\end{array}$ \\
\hline 1 & $15-27$ & 3 & 10,7 \\
\hline 2 & $28-40$ & 4 & 14,3 \\
\hline 3 & $41-53$ & 3 & 10,7 \\
\hline 4 & $54-66$ & 4 & 14,3 \\
\hline 5 & $67-79$ & 7 & 25 \\
\hline 6 & $80-92$ & 7 & 25 \\
\hline & Jumlah & 28 & 100 \\
\hline
\end{tabular}

Berdasarkan data di atas diperoleh kesimpulan bahwa bersarnya rata-rata nilai siswa mengalami kenaikan dari $21,43 \%$ dari sebelum dilakukan tindakan, selanjutnya hasil belajar siswa meningkat menjadi $50 \%$ setelah dilakukan pembelajaran Matematika melalui pendekatan scientific dengan pembelajran cooperative learning di kelas IV Terdapat 14 siswa yang nilainya belum mencapai KKM yang sudah ditetapkan, yaitu < 70. Sedangkan 14 siswa lainnya telah mencapai nilai ketuntasan minimal.

Pada siklus I belum dicapai ketuntasan berdasarkan target yang diinginkan yaitu lebih dari 75\%. Selanjutnya peneliti menaiikan kinerja disiklus II. Agar dapat meningkatkan hasil belajar yang diharapkan. 
Tabel 3

Frekuensi data nilai siswa kelas IV.C SDN 58 Lubuklinggau pada siklus II

\begin{tabular}{cccc}
\hline No & Interval & Frekuensi & $\begin{array}{c}\text { Persentase } \\
(\%)\end{array}$ \\
\hline 1 & $19-31$ & 1 & 3,6 \\
\hline 2 & $32-44$ & 3 & 10,7 \\
\hline 3 & $45-57$ & 2 & 7,1 \\
\hline 4 & $58-70$ & 5 & 17,9 \\
\hline 5 & $71-83$ & 10 & 35,7 \\
\hline 6 & $84-96$ & 7 & 25 \\
\hline & Jumlah & 28 & 100 \\
\hline
\end{tabular}

Dari tabel diatas dapat dilihat bahwa siswa yang memperoleh nilai $\geq \mathrm{KKM}$ ada 17 siswa atau 60,7\%, sedangkan 11 siswa masih dibawah nilai KKM. Dengan demikian nilai rata-rata siswa dari hasil tes yang diberikan diakhir pembelajaran Matematika melalui pendekatan scientific dengan pembelajran cooperative learning kembali mengalami peningkatan dari siklus sebelumnya.

Dimana pada siklus I terdapat $50 \%$ siswa yang nilainya $\geq 70$, sedangkan pada siklus II meningkat menjadi $60,7 \%$. Pada siklus II ini masih ditemukan kekurangan yang perlu diperbaiki pada siklus II, yaitu: siswa belum begitu aktif dalam pembelajaran berkelompok, karena dalam pembelajaran berkelompok siswa masih perlu dibimbing oleh guru.

Tabel 4

Frekuensi data nilai siswa kelas IV.C SDN 58 Lubuklinggau pada siklus III

\begin{tabular}{cccc}
\hline No & Interval & Frekuensi & $\begin{array}{c}\text { Persentase } \\
(\%)\end{array}$ \\
\hline 1 & $20-32$ & 1 & 3,6 \\
\hline 2 & $33-45$ & 1 & 3,6 \\
\hline 3 & $46-58$ & 1 & 3,6 \\
\hline 4 & $59-71$ & 2 & 7,1 \\
\hline 5 & $72-84$ & 13 & 46,5 \\
\hline 6 & $85-97$ & 10 & 35,7 \\
\hline & Jumlah & 28 & 100 \\
\hline
\end{tabular}

Berdasarkan data diatas dapat ditarik kesimpulan dari siklus III bahwa peserta didik kelas IV.C dengan jumlah 24 siswa mendapatkan nilai $\geq 70$. Artinya sudah mencapai target yang diharapkan karena siswa yang tuntas mencapai $85,71 \%$. Dengan demikian hanya 4 siswa atau $14,29 \%$ siswa yang nilainya < KKM, yaitu 70. Setelah melewati 3 siklus kemudian data dibandingkan dari ketuntasan hasil belajar siswa dilihat dari peningkatan hasil rata-rata siswa dari kondisi awal hingga siklus ke-3.

Berdasarkan analisa di atas dapat diketahui bahwa upaya meningkatkan hasil belajar Matematika melalui pembelajaran Matematika melalui pendekatan scientific dengan pembelajran cooperative learning pada siswa kelas IV SDN 58 Lubuklinggau berhasil dilakukan dengan baik dengan pelaksanaan 3 siklus. Pembelajaran Matematika melalui pendekatan scientific dengan pembelajran cooperative learning pada siswa kelas IV SDN 58 Lubuklinggau. Mampu meningkatkan hasil belajar siswa karena nilai ketuntasan siswa selalu mangalami peningkatan dari $21,4 \%$ menjadi $50 \%$ pada siklus I, kemudian meningkat kembali menjadi $60,7 \%$ pada siklus II, dan pada siklus III meningkat lagi menjadi $85,7 \%$. Hal ini sejalan dengan penelitian yang 
dilakukan oleh Yuni Karsih Asmi Universitas Sebelas Maret yang mendapatkan hasil pada penerapan model pembelajaran kooperatif teknik Make a Match dengan pendekatan Scientific dapat meningkatkan pemahaman konsep menyederhanakan pecahan pada siswa kelas IV SDN Ponowaren 02. Berikut animasi yang ditampilkan saat pembelajaran berlangsung:

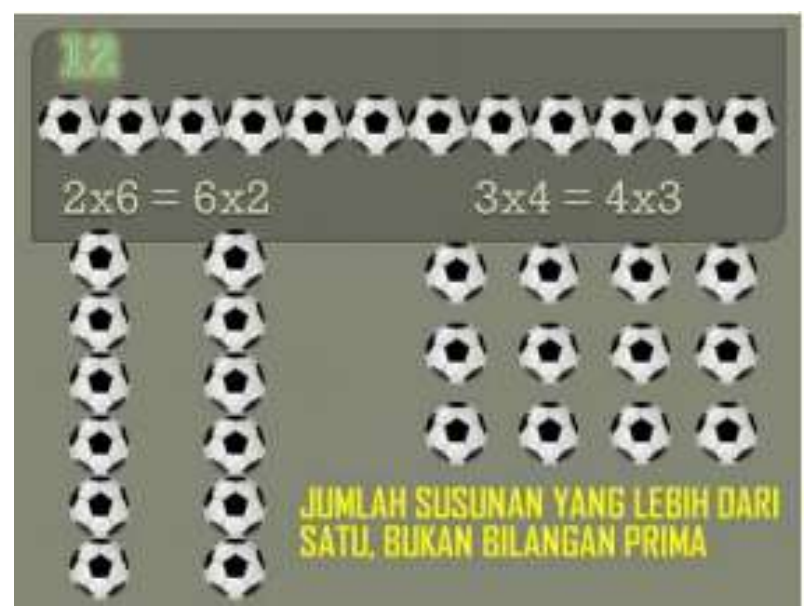

Gambar 1

Materi Bilangan Prima

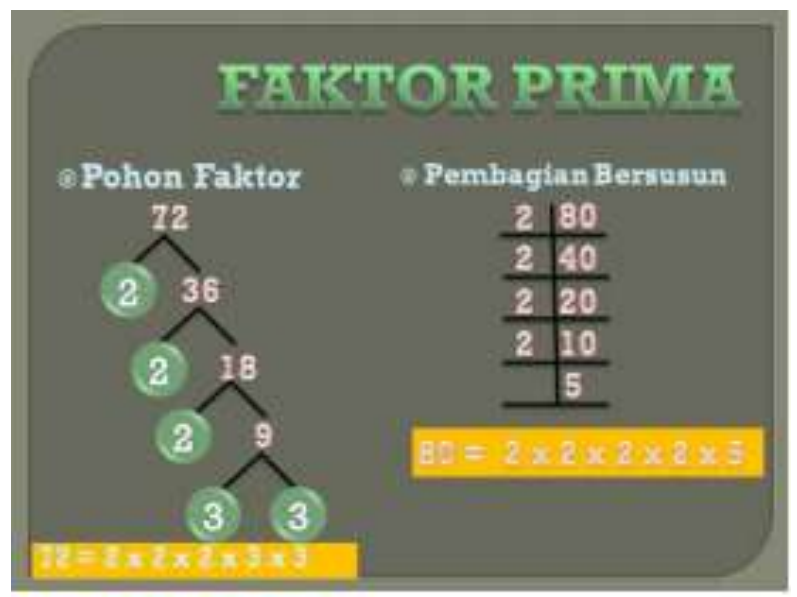

Gambar 2

Materi Faktor Prima

Keaktifan siswa juga menjadi salah satu variabel yang diukur dalam penelitian ini, karena aktivitas siswa juga dapat mempengaruhi hasil belajar. Untuk mengetahui keaktifan siswa dilakukan dengan menggunakan lembar observasi yang dilakukan pada saat pembelajaran Matematika melalui pendekatan scientific dengan pembelajran cooperative learning berlangsung.

Tabel 5.

Frekuensi data keaktifan siswa kelas IV.C SDN 58 Lubuklinggau pada siklus I

\begin{tabular}{cccc}
\hline Skor & Frekuensi & $\begin{array}{c}\text { Persentase } \\
(\%)\end{array}$ & Interpretasi \\
\hline 1 & 3 & 10,7 & TT \\
\hline 2 & 8 & 28,6 & TD \\
\hline 3 & 17 & 60,7 & TS \\
\hline 4 & 0 & 0 & ST \\
\hline Jml & $\mathbf{2 8}$ & $\mathbf{1 0 0}$ & \\
\hline
\end{tabular}


Keterangan:

TT : Tidak Tampak

TD : Tampak Sedikit

TS : Tampak Sedang

ST : Sangat Tampak

Nilai keaktifan siswa dapat dilihat pada hasil observasi dalam pembelajaran Matematika melalui pendekatan scientific dengan pembelajran cooperative learning pada siklus I, dimana persentase keaktifan terdapat 8 siswa atau 28,6\% tampak sedikit dan $60,7 \%$ tampak sedang atau kategori baik.

Masih terdapat 3 siswa yang belum tampak keaktifannya. Hal ini disebabkan pada saat pembelajaran berlangsung siswa belum mampu beradaptasi dengan cara belajar berkelompok.

Tabel 6

Frekuensi data keaktifan siswa kelas IV.C SD N 58 Lubuklinggau pada siklus II

\begin{tabular}{cccc}
\hline Skor & Frekuensi & $\begin{array}{c}\text { Persentase } \\
(\%)\end{array}$ & Interpretasi \\
\hline 1 & 1 & 3,6 & TT \\
\hline 2 & 6 & 21,4 & TD \\
\hline 3 & 13 & 46,4 & TS \\
\hline 4 & 8 & 28,6 & ST \\
\hline Jml & $\mathbf{2 8}$ & $\mathbf{1 0 0}$ & \\
\hline
\end{tabular}

Dari tabel diatas dapat dilihat bahwa keaktifan siswa mengalami peningkatan dari siklus sebelumnya. Siswa yang tidak tampak berkurang tinggal 1 siswa atau 3,6\%. Terlihat juga terdapat 8 siswa atau $28,6 \%$ sangat tampak keaktifannya. Karena masih ada siswa yang tidak tampak dan baru tampak sedikit keaktifannya yaitu $21,4 \%$ maka pembelajaran akan dioptimalkan kembali agar keaktifan semua siswa minimal tampak sedang.

Tabel 7.

Frekuensi data keaktifan siswa kelas IV.C SD N 58 Lubuklinggau pada siklus III

\begin{tabular}{cccc}
\hline Skor & Frekuensi & $\begin{array}{c}\text { Persentase } \\
(\%)\end{array}$ & Interpretasi \\
\hline 1 & 0 & 0 & TT \\
\hline 2 & 0 & 0 & TD \\
\hline 3 & 12 & 42,9 & TS \\
\hline 4 & 16 & 57,1 & ST \\
\hline Jml & $\mathbf{2 8}$ & $\mathbf{1 0 0}$ & \\
\hline
\end{tabular}

Pada siklus ke-3 dapat terlihat bahwa tidak ada lagi siswa yang tidak aktif, keaktifan siswa semakin meningkat. Dari tabel tersebut semua siswa terliah aktif dengan persentase 0 siswa yang tidak akitf, terdapat 12 siswa atau 42,9\% siswa yang tampak sedang atau kategori baik dan sisanya 16 siswa atau $57,1 \%$ sangat tampak keaktifannya.

\section{PEMBAHASAN}

Dalam penelitian ini pada siklus I ditemukan beberapa kekurangan atau kelemahan yang terjadi saat melaksanakan pembelajaran Matematika melalui pendekatan scientific dengan pembelajran cooperative learning, sehingga perlu diperbaiki pada siklus II, antara lain: guru belum 
mengelolah waktu secara efesien dengan materi dan evaluasi yang disajikan. Pada siklus II didapat ketuntasan siswa belum mencapai hasil yang diharapkan, maka dari itu pada siklus III akan dilakukan perbaikan lagi agar hasil pembelajaran perserta didik meningkat dengan target yang diharapkan.

Setelah melewati 3 siklus pada pembelajaran kemudian data dibandingkan dari ketuntasan hasil belajar siswa dilihat dari peningkatan hasil rata-rata siswa dari kondisi awal hingga siklus ke-3. Hal ini terlihat dari adanya peningkatan ketuntasan belajar siswa, pada prasiklus siswa yang mencapai nilai ketuntasan belajar (KKM) 38,10\%, pada siklus I mengalami kenaikan menjadi 76,19\% dan pada siklus II meningkat lagi menjadi 95,24\%. Melihat dari hasil penelitian yang dilakukan oleh peneliti maupun penelitian yang telah dilakukan sebelumnya bahwa pembelajaran Matematika melalui pendekatan scientific dengan pembelajaran cooperative learning cukup efektif digunakan dalam pembelajaran Matamatika. Perbandingan data ketuntasan belajar siswa dapat dilihat dari gambar berikut.



Gambar 3

Grafik Perbandingan data frekuensi rata-rata nilai siswa

Dari data keaktifan siswa yang telah disajikan dalam tabel dari siklus I - III dapat dibandingkan untuk melihat peningkatanya. Data peningkatan keaktifan siswa tiap siklus disajikan dengan diagram berikut.

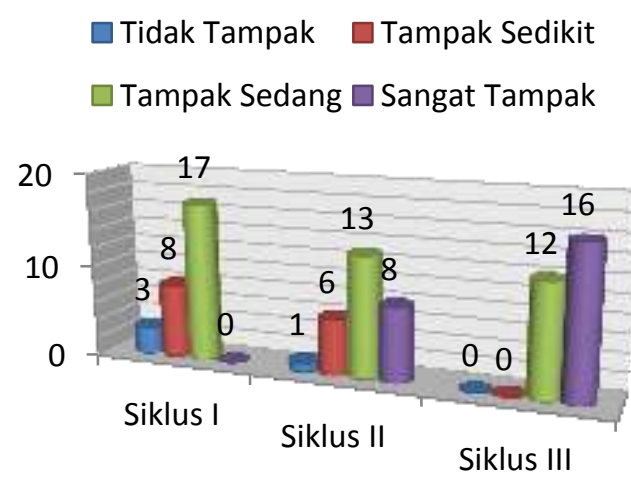

Gambar 4

Diagram Perbandingan data frekuensi rata-rata keaktifan siswa

Berdasarkan analisis dari diagram diatas bahwa keaktifan siswa terus mengalami peningkatan setelah dilakukan pembelajaran Matematika melalui pendekatan scientific dengan pembelajran cooperative learning. Pada siklus I terdapat 3 siswa yang belum tampak keaktifannya 
kemudian di siklus II berkurang menjadi 1 siswa hingga siklus III tidak terdapat siswa yang tidak tampak dengan skala tidak tampak $0 \%$.

Dapat dilihat juga dari keaktifan siswa yang sangat tampak pada tiap siklus mengalami peningkatan. Pada siklus I tidak ada siswa yang begitu antusias atau sangat tampak, pada siklus II mulai terlihat mengalami peningkatan, terdapat 8 anak yang sangat aktif dalam belajar berkelompok. Hingga diakhir siklus meningkat kembali menjadi 16 siswa atau 57,1\% yang sangat aktif. pembelajaran Matematika melalui pendekatan scientific dengan pembelajran cooperative learning cukup efektif digunakan dalam pembelajan untuk membuat siswa lebih aktif dalam belajar dan meningkatkan hasil belajar siswa.

\section{SIMPULAN}

Penerapan melaui pendekatan scientific dengan pembelajran cooperative learning dalam pembelajaran Matematika dapat meningkatkan hasil belajar siswa kelas IV SDN 58 Lubuklinggau tahun pelajaran 2017/2018. Penerapan melalui pendekatan scientific dengan pembelajran cooperative learning dalam pembelajaran Matematika dapat meningkatkan keaktifan siswa kelas IV SDN 58 Lubuklinggau tahun pelajaran 2017/2018.

\section{DAFTAR PUSTAKA}

Bintari dkk. (2014). Pembelajaran Bahasa Indonesia berdasarkan Pendekatan Saintifik (Problem Based Learning) Sesuai kurikulum 2013 di Kelas VII SMP Negeri 2 Amlapura. Journal Program Pascasarjana Universitas Pendidikan Ganesha. 3(1).

Harianti T, Suro S, Faradillah A. (2018). Perbedaan Hasil Belajar Matematika Siswa dengan Model Discovery Learning dan Model Pembelajaran Kooperatif Tipe Student Team Achievement Division (STAD) berbasis LKPD di SMP Muhammadiyah 4 Cipondoh. Semiar Nasional Pendidikan Matematika 2018. 2(1).

Heruman. (2008). Model Pembelajaran Matematika di Sekolah Dasar. Bandung: PT Remaja Rosdakarya.

Indrastoeti J, Mahfud H. (2015). Pembelajaran Kooperatif dengan Pendekatan Experiental Learning untuk Meningkatkan Keterampilan Sosial. Jurnal Mimbar Sekolah Dasar Universitas Sebelas Maret. 2(2).

Rahmawati I, Syahrilfuddin, Noviana E. (2016). The implementation of project based learning Model on improving mathematics learning outcomes Of the fifth grade students at 018 primary school Sungai keranji. Universitas Riau. Hal 1-10.

Sugiyono. (2009). Metode Penelitian Kuantitatif, Kualitatif dan R\&D. Bandung : Alfabeta. 